\title{
Comparison of the visual analog scale (vas) and the scaling pain relief (spr) measurements in the assessment of the results of spinal cord stimulation trial and therapy: A prospective study
}

\author{
Y. Eugene Mironer ${ }^{*}$, John Satterthwaite, Kelby J. Hutcheson
}

Carolinas Center for Advanced Management of Pain, SC/NC, Greenville, USA; *Corresponding Author: Y1917@aol.com

Received 10 November 2013; revised 17 December 2013; accepted 7 January 2014

Copyright (c) 2014 Y. Eugene Mironer et al. This is an open access article distributed under the Creative Commons Attribution License, which permits unrestricted use, distribution, and reproduction in any medium, provided the original work is properly cited. In accordance of the Creative Commons Attribution License all Copyrights (C) 2014 are reserved for SCIRP and the owner of the intellectual property Y. Eugene Mironer et al. All Copyright (C) 2014 are guarded by law and by SCIRP as a guardian.

\section{ABSTRACT}

Objectives: The goal of this study was to compare the results of evaluating the success of spinal cord stimulation (SCS) using the Visual Analog Scale (VAS) and a Scaling Pain Relief (SPR) measurement. Methods: This prospective study included 29 patients, who were considered good candidates for an SCS trial. In the immediate post trial period, immediate post implant period, and one-month post implant period, pain relief was assessed by VAS percent change and using an SPR measurement (direct patient report of pain relief). Statistical analysis of the results included a repeated measures analysis of variance (ANOVA) comparing VAS percent change versus direct patient report of percentage of pain relief (SPR) at the post trial, post implant, and one month follow-ups for all patients that received a permanent implant. Results: Twenty-one patients had a successful trial and 20 were implanted with a permanent system. There was a strong positive correlation between the two pain relief measures at every measured timepoint. Direct patient reports of percentage of pain relief (SPR) were statistically higher than VAS percent change at the post trial period. Seven patients were considered good candidates for implantation based on the SPR measurement, but not VAS percent reduction. These patients went on to achieve clinically significant changes. Discussion: SPR measurements such as direct patient reports of pain relief should be considered in place of VAS percent change when determining SCS trial success.

\section{KEYWORDS}

Spinal Cord Stimulation; Results Measurements; VAS

\section{INTRODUCTION}

Spinal cord stimulation (SCS) is a very important, and progressively expanding part of the pain management continuum. The modern era of SCS had its beginning with the first report of spinal cord stimulation using an intrathecally placed lead in 1967 [1]. Over the next thirty years, this modality underwent significant transformation and expansion in both the use and variety of technologies. In the beginning of the $21^{\text {st }}$ century, it has become a very popular, widely used mode of treatment [2,3], and our knowledge in this field has increased tremendously. At the same time, this improvement in the scope of knowledge has demonstrated that we still have many unanswered questions. One of these issues is the selection of appropriate patients for spinal cord stimulator implantation. The ability to go through a minimally invasive trial, in order to determine the future success of implantation, is an extremely attractive feature of this modality of treatment. The trial period has undergone many improvements over the years. It has been transformed from an "on the table trial" for a few minutes, to an ambulatory trial, lasting from a few days to a period of a few weeks. In the latter case, the trial lead is internalized and used as a "permanent" lead if the patient goes on to implantation. Currently, the most common method of SCS trialing is placement of a temporary, percutaneous lead 
for a period of 3 - 7 days [4]. Despite these changes in the technique and duration of the trial, the definition of a successful trial has stayed the same: $50 \%$ or better pain reduction based on a comparison of Visual Analog Scale (VAS) measurements before and after the procedure [5]. The same criterion is also used for the assessment of outcomes of permanent implantation, but with the addition of a satisfaction measurement [6].

Data collected by the author's personal communication with 78 implanters revealed that the vast majority did not rely on the VAS in assessing the results of a trial, but rather on direct patient reports of pain relief such as the Scaling Pain Relief (SPR) measurement. The SPR measurement is a direct rating of pain after certain treatment modalities expressed in percentage of pain relief where patients are asked to estimate the percentage of pain relief they experience or a "categorical" VAS with anchors of "no change" to "100 pain relief" may also be used. In addition, we collected information from sales representatives working with St. Jude Medical Neuromodulation, Inc. (Plano, TX) and Medtronic, Inc. (Minneapolis, MN). They obtained information from an additional 158 implanters. Sixty-eight percent of these implanters never use the VAS during the trial as an outcome measurement, while only $2 \%$ rely solely on the VAS. This stresses the strong need to reassess the use of different methods of pain measurement in the practice of SCS.

Our personal method of assessing the degree of pain relief with SCS has changed over the years from the VAS to the SPR measurement. This was the result of our group's experience in a few thousands patients, that led us to believe that the VAS score was not the easiest, and probably not the most accurate, way of measuring the success of the SCS trial.

To confirm this observation, we performed a prospective study comparing the utility of the VAS and the SPR measurement in patients who were scheduled for an SCS trial.

\section{MATERIALS AND METHODS}

Twenty-nine consecutive patients, with a variety of chronic, intractable pain problems and who were considered to be good candidates for SCS trial, were included in the study. All SCS trials took place within a 45 day period. All patients were asked to measure their pain using the VAS immediately prior to the trial (baseline). Three days after the SCS trial procedure, prior to removal of the trial lead, all patients again quantified their pain using the VAS. VAS percent change was calculated by subtracting the post-trial VAS score from the baseline VAS score and dividing by the baseline VAS score. Patients were also asked to assess the degree of pain relief with SCS using the SPR measurement of direct patient report of percentage of pain relief. Patients that reported a $50 \%$ or greater reduction in pain on the SPR measurement at the end of the trial period were considered good candidates for implantation. These patients were implanted an SCS system that consisted of either a percutaneous or laminotomy lead. One week after permanent implant, patients again rated their pain level on the VAS and their pain relief with the SPR measurement. This was repeated one month post implant.

At all three points-after the trial, after the implant, and at one month post implant-we compared pain relief measured by the SPR measurement and the decrease in pain measured by the difference between baseline VAS and VAS scores at the three subsequent points of measurement.

\section{Statistical Analysis}

Pearson correlations were performed to characterize the relationship between VAS percent reduction and the SPR measurement of direct patient report of percentage of pain relief at all timepoints. A paired samples $t$-test was conducted to compare VAS percent reduction and the SPR measurement at the post-trial period for all patients that underwent a trial. Statistical analysis of the post-implant results was performed using a repeated measures analysis of variance (ANOVA) comparing VAS percent change versus direct report of pain relief (SPR) at the post trial, post implant, and one month time intervals. Differences were considered significant at $p$ values $<0.05$.

\section{RESULTS}

Of the 29 patients that underwent a trial, eleven patients (37.9\%) were male and eighteen (62.1\%) were female. Pain relief percentages for VAS and the SPR measurement at the post-trial period are shown in Figure 1. The mean $( \pm \mathrm{SD})$ VAS percent change at the post-trial assessment was $41.5( \pm 26.1) \%$ and the mean $( \pm S D)$ direct patient report of pain relief was $51.2( \pm 29.5) \%$. This

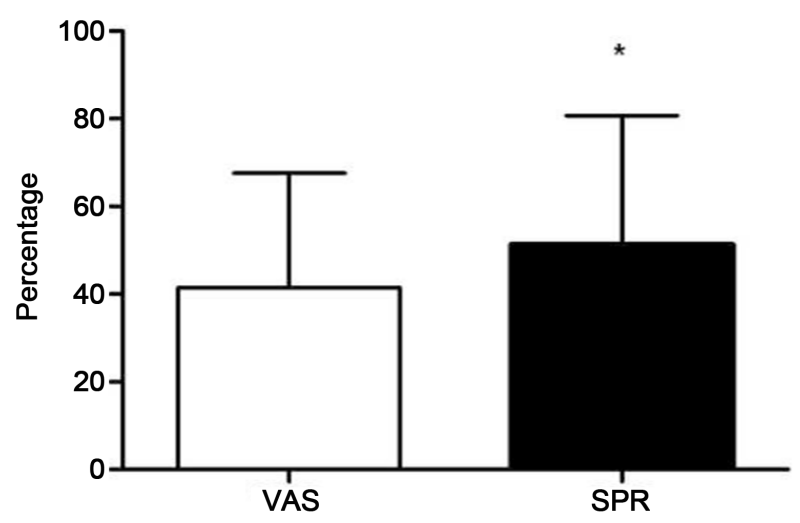

Figure 1. Pain relief percentages for VAS and the SPR measurement at the post-trial period. 
difference was statistically significant, $t(28)=-4.67, p<$ 0.001 . Twenty-one out of 29 patients had a successful trial, defined as achieving a $50 \%$ or greater reduction on the SPR measurement, and twenty underwent implantation of a permanent SCS system. In contrast, only 13 patients achieved a $50 \%$ or greater reduction on the VAS during the trial period. Nineteen patients (65.5\%) achieved a greater percentage of pain relief as measured by the SPR measurement than by the VAS, 7 patients (24.1\%) achieved the same percentage of pain relief on both measures and 3 patients (10.3\%) of patients achieved a lower percentage of pain relief as measured by the SPR measurement than by the VAS.

Of the 20 patients that received permanently implantation of the SCS system, six (30\%) were implanted with a laminotomy lead and the remaining 14 patients (70\%) were implanted with a percutaneous lead. Mean VAS percent change SPR for all implanted patients $(\mathrm{N}=20)$ at the post-trial, 1 week and 1 month assessment are shown in Figure 2. The mean $( \pm S D)$ VAS percent change for these patients at the post-trial assessment was 54.0 $( \pm 18.7) \%$ and the mean $( \pm S D)$ direct patient report of pain relief was $66.8( \pm 18.7) \%$. At the 1 week assessment, the mean $( \pm \mathrm{SD})$ VAS percent change was $46.8( \pm 22.0) \%$ and the mean $( \pm S D)$ direct patient report of pain relief was $55.0( \pm 23.2) \%$. The VAS percent change and the direct patient report of pain relief remained stable at the 1 month assessment with patients reporting a mean $( \pm \mathrm{SD})$ VAS percent change of $44.5( \pm 23.4) \%$ and a mean $( \pm S D)$ direct report of pain relief of $52.3( \pm 28.6) \%$. Direct patient reports of percentage of pain relief (SPR) were statistically higher than VAS percent change only at the post trial period for all patients that were permanently implanted, $F(1,38)=4.61, p<0.039$. There were no significant differences in pain relief measurements at any timepoint between percutaneous and laminotomy implants, all Fs $<0.01, \mathbf{p}>0.05$.

An evaluation of the 7 patients that achieved a $50 \%$ or

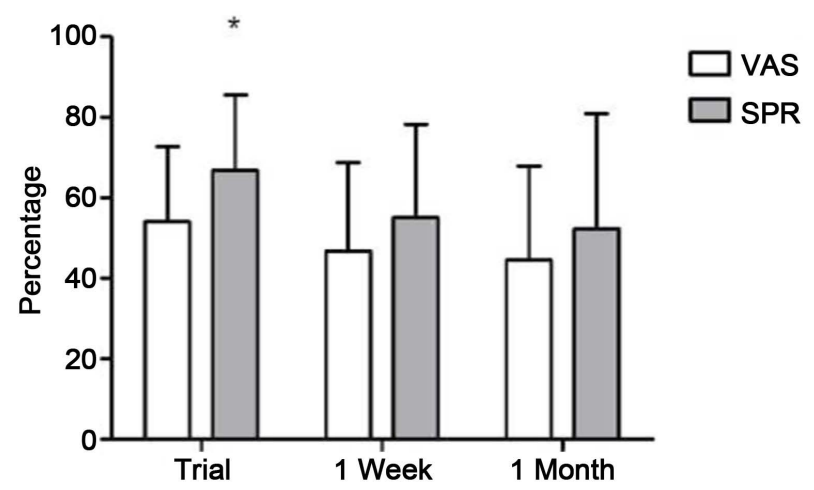

Figure 2. Mean VAS percent change and direct patient report of pain relief percentage for all implanted patients $(\mathrm{N}=20)$ at the post-trial, 1 week and 1 month assessment. greater reduction on the SPR measurement but not the VAS showed that these patients achieved clinically significant results after being permanently implanted (23). These patients achieved a mean ( \pm SD) VAS percent change of $34.5( \pm 13.8) \%$ and $31.3( \pm 10.3) \%$ a mean ( \pm SD) direct report of pain relief of $41.4( \pm 13.6) \%$ and $32.9( \pm 13.9) \%$ at 1 week and 1 month, respectively. Their VAS scores improved from a mean $( \pm \mathrm{SD})$ of $8.7( \pm 0.5)$ $\mathrm{cm}$ to $5.7( \pm 1.4)$ at 1 week and $6.0( \pm 1.2)$ at 1 month. This represents a mean $( \pm \mathrm{SD})$ change of $3.0( \pm 1.3)$ at 1 week and $2.7( \pm 1.0)$ at 1 month, which is within range of what is considered clinically significant.

There was a strong positive correlation between the two pain relief measures at every measured timepoint with the strongest correlation at the post trial period, $r(27)$ $=0.93, p<0.01$ for all patients that underwent a trial $(\mathrm{N}$ = 29) and at one month after the implant for patients that were permanently implanted $(\mathrm{N}=20), r(18)=0.883, p<$ 0.01 . This indicates that the SPR measurement of direct patient report of percentage of pain relief is highly correlated with VAS percent change and can be considered a viable substitute for the VAS in the evaluation of pain relief during SCS.

\section{DISCUSSION}

Patient selection and an adequate trial are the most crucial components of successful treatment with SCS. A vital part of this process is a correct interpretation of the SCS trial results with regards to pain relief. The VAS has been the "gold standard" method of objectively assessing this relief [7]. The difference in VAS scores before and after the procedure should be equal to or exceed $50 \%$, in order to qualify the trial as being successful [5]. It is not surprising that the VAS was selected for this purpose. It is the most popular and widely used pain measurement tool. A review of randomized controlled studies of musculoskeletal pain showed that the VAS was, by far, the most commonly used method of quantifying outcomes [8]. Other authors also claim that the VAS is superior to other pain scaling methods $[9,10]$. One study revealed that their study subjects also preferred the VAS to numeric rating scales (NRS) [11].

However, a closer look at the literature dedicated to the measurement of pain shows that the "superiority" of the VAS is not a universally accepted concept. One study showed that $7 \%$ to $11 \%$ of the patients were unable to complete the VAS or found it confusing $[12,13]$. It turned out to be an even bigger problem in an older population. Multiple studies confirmed that older subjects had more difficulty completing the VAS and, as a result, the VAS had poorer psychometric properties than other scales [13-16]. More recent studies have also shown the advantages of using the NRS, and some other measurements, 
instead of the VAS [17-21]. Not surprisingly, a panel of experts has also suggested using the NRS, instead of the VAS, as a method of assessment of pain intensity in outcome measurement studies [22].

There are even more issues related to the use of the VAS as a measure of pain relief after a specific treatment. Patients without chronic pain have a reasonably accurate memory for pain, such as postsurgical pain, for up to a week $[23,24]$. For chronic pain conditions, when the intensity of pain is being compared over a period of time, the situation is completely different. It was shown that the intensity of the current pain produced a distortion of the memory of prior pain, independent of treatment outcome [25]. Another author believes that the use of the VAS as an indicator of pain relief is not the best choice [26]. The validity of the VAS in the assessment of procedural outcomes in the chronic pain population is also unsatisfactory according to some studies [26,27].

A more optimal method of measuring the results of an analgesic treatment seems to be the use of the SPR, since "it does not require a pain-challenge stimulus and it does not rely on pain scores" [28]. While it is not an optimal tool in post-operative pain, it works much better in the chronic pain environment when the patient is well aware of his pain, which is relatively constant [28].

In the only comparison between the VAS and SPR in SCS patients [29], the SPR not only showed a significantly higher degree of pain relief ( $63 \%$ vs. $46 \%)$, but also showed an increase in treatment success, based on pain relief from $59 \%$ to $83 \%$, which was much more in line with treatment success in the same group measured by patient satisfaction (87\%). Review of the literature confirms that the majority of studies have a similar discrepancy between satisfaction rate and successful reduction of pain level, measured by the VAS (29).

One more important issue for future consideration is the arbitrarily selected " $50 \%$ pain reduction" as an indication of successful treatment. As eloquently stated by Seres [30], "by choosing such a low level for acceptable outcome, are we treating more our patients' needs or our requirements for something upon which to justify what we do?”

\section{CONCLUSION}

In our opinion, the comparative use of VAS scores to measure the success of a spinal cord stimulation trial, or permanent implant, should be replaced with the SPR measurement of direct patient report of percentage of pain relief.

\section{ACKNOWLEDGEMENTS}

The authors want to express their gratitude to Stephanie Washburn, Eric Skoloff and Roni Diaz for their invaluable assistance in perform- ing and publishing this study.

\section{REFERENCES}

[1] Shealy, C.N., Mortimer, J.T. and Reswick, J.B. (1967) Electrical inhibition of pain by stimulation of the dorsal columns. Anesthesia and Analgesia, 46, 489-491. http://dx.doi.org/10.1046/j.1525-1403.2000.00059.x

[2] Wetzel, F.T., Hassenbusch, S., Oakley, J.C., et al. (2000) Treatment of chronic pain in failed back surgery patients with spinal cord stimulation: A review of current literature and proposal for future investigation. Neuromodulation, 3, 59-74.

http://dx.doi.org/10.1046/j.1525-1403.2002.02027.x

[3] Sharan, A., Cameron, T. and Barolat, G. (2002) Evolving patterns of spinal cord stimulation in patients implanted for intractable low back and leg pain. Neuromodulation, 5, 161-179.

[4] Mironer, Y.E. (2002) Neurostimulation techniques. In: Tollison, C.D., Satterthwaite, J.R. and Tollison, J.W., Eds., Practical Pain Management, Lippincott, Philadelphia, 155-173.

[5] Burchiel, K.J., Anderson, V.C., Brown, F.D., et al. (1996) Prospective, multicenter study of spinal cord stimulation for relief of chronic back and extremity pain. Spine, 21, 2786-2794.

http://dx.doi.org/10.1097/00007632-199612010-00015

[6] North, R.B. and Guarino, A.H. (1999) Spinal cord stimulation for failed back surgery syndrome: Technical advances, patient selection and outcome. Neuromodulation, 2, 171-178.

http://dx.doi.org/10.1046/j.1525-1403.1999.00171.x

[7] Turner, J.A., Loeser, J.D. and Bell, K.G. (1995) Spinal cord stimulation for chronic low back pain: A systematic literature synthesis. Neurosurgery, 37, 1088-1096. http://dx.doi.org/10.1227/00006123-199512000-00008

[8] Litcher-Kelly, L., Martino, S.A., Broderick, J.E., et al. (2007) A systematic review of measures used to assess chronic musculoskeletal pain in clinical and randomized controlled clinical trials. The Journal of Pain, 8, 906-913. http://dx.doi.org/10.1016/j.jpain.2007.06.009

[9] Price, D.D., Bush, F.M., Long, S. and Harkins, S.W. (1994) A comparison of pain measurement characteristics of mechanical visual analog and simple numeric scales. Pain, 56, 217-226. http://dx.doi.org/10.1016/0304-3959(94)90097-3

[10] Price, D.D., Riley, J.L. and Wade, J.B. (2001) Psychophysical approaches to measurement of the dimensions and stages of pain. In: Turk, D.C. and Melzack, R., Eds., Handbook of Pain Assessment (2nd edition), The Guilford Press, New York, 53-75.

[11] Price, D.D., Patel, R., Robinson, M.E. and Staud, R. (2008) Characteristics of electronic visual analogue and numeric scales for ratings of experimental pain in healthy subjects and fibromyalgia patients. Pain, 140, 158-166. http://dx.doi.org/10.1016/j.pain.2008.07.028

[12] Revill, S.I. (1976) The reliability of a linear analog for evaluating pain. Anaesthesia, 31, 1191-1198. 
http://dx.doi.org/10.1111/j.1365-2044.1976.tb11971.x

[13] Kremer, E., Atkinson, J.H. and Ignelzi, R.J. (1980) Measurement of pain: Patient preference does not confound pain measurement. Pain, 10, 241-248. http://dx.doi.org/10.1016/0304-3959(81)90199-8

[14] Gagliese, L. and Melaka, R. (1997) Age differences in the quality of chronic pain: A preliminary study. Pain Research \& Management, 2, 157-162.

[15] Herr, K.A. and Mobily, P.R. (1993) Comparison of selected pain assessment tools for use with elderly. Applied Nursing Research, 6, 39-46. http://dx.doi.org/10.1016/S0897-1897(05)80041-2

[16] Jensen, M.P., Karoly, P. and Braver, S. (1986) The measurement of clinical pain intensity: A comparison of six methods. Pain, 27, 117-126. http://dx.doi.org/10.1016/0304-3959(86)90228-9

[17] Gagliese, L. and Katz, J. (2003) Age differences in postoperative pain are scale dependent: A comparison of measures of pain intensity and quality in younger and older surgical patients. Pain, 103, 11-20. http://dx.doi.org/10.1016/S0304-3959(02)00327-5

[18] Gagliese, L. and Melzack, R. (2003) Age related differences in the qualities but not the intensity of chronic pain. Pain, 104, 597-608. http://dx.doi.org/10.1016/S0304-3959(03)00117-9

[19] Gagliese, L., Weizblit, N., Ellis, W. and Chan, V.W.S. (2005) The measurement of postoperative pain: A comparison of intensity scales in younger and older surgical patients. Pain, 117, 412-420. http://dx.doi.org/10.1016/j.pain.2005.07.004

[20] Herr, K.A., Spratt, K., Mobily, P.R. and Richardson, G. (2004) Pain intensity assessment in older adults: Use of experimental pain to compare psychometric properties and usability of selected pain scales with younger adults. The Clinical Journal of Pain, 20, 207-219. http://dx.doi.org/10.1097/00002508-200407000-00002

[21] Peters, M.L., Patijn, J. and Lame, I. (2007) Pain assessment in younger and older pain patients: Psychometric properties and patient preference of five commonly used measures of pain intensity. Pain Medicine, 8, 601-610. http://dx.doi.org/10.1111/j.1526-4637.2007.00311.x

[22] Dworkin, R.H., Turk,, D.C., Farrar,, J.T., et al. (2005) Core outcome measures for chronic pain clinical trials: IMMPACT recommendations. Pain, 113, 9-19. http://dx.doi.org/10.1016/j.pain.2004.09.012

[23] Hunter, M., Philips, C. and Rachman, S. (1979) Memory for pain. Pain, 6, 35-46. http://dx.doi.org/10.1016/0304-3959(79)90138-6

[24] Kwilosz, D.M., Gracely, R.H. and Torgerson, W.S. (1984) Memory for postsurgical dental pain. Pain, 2, S426. http://dx.doi.org/10.1016/0304-3959(84)90761-9

[25] Eich, E. (1985) Memory for pain: Relation between past and present pain intensity. Pain, 23, 375-380. http://dx.doi.org/10.1016/0304-3959(85)90007-7

[26] Carlsson, A.M. (1983) Assessment of chronic pain. Aspects of the reliability and validity of the visual analog scale. Pain, 16, 87-101. http://dx.doi.org/10.1016/0304-3959(83)90088-X

[27] Kremer, E.F., Block, A.J. and Gaylor, M.S. (1980) Behavioral approaches to treatment of chronic pain: The inaccuracy of patient self-report measures. Archives of Physical Medicine and Rehabilitation, 62, 188.

[28] Chapman, C.R. and Syrjala, K.L. (1990) Measurement of pain. In: Bonica, J.J., Ed., The Management of Pain (2nd edition), Lea\&Febiger Publishers, Philadelphia, 580-594.

[29] Mironer, Y.E., Satterthwaite, J.R., Lewis, E.M., et al. (2008) Efficacy of a single, percutaneous, across midline, octrode lead using a "midline anchoring" technique in the treatment of chronic low back and/or lower extremity pain. Neuromodulation, 11, 286-295. http://dx.doi.org/10.1111/j.1525-1403.2008.00178.x

[30] Seres, J.L. (1999) The fallacy of using 50\% pain relief as the standard for satisfactory pain treatment outcome. Pain Forum, 8, 183-188. http://dx.doi.org/10.1016/S1082-3174(99)70005-X 